\title{
PREFACE
}

\section{Recommended standards for newborn intensive care unit design}

\author{
GI Martin \\ Editor Emeritus, Member of the Sixth Consensus Committee \\ E-mail: gimartin@pol.net
}

Journal of Perinatology (2006) 26, S1. doi:10.1038/sj.jp.7211582

'It is better to light one candle than curse the darkness'

Motto of the Christopher Society

This is the third supplement to the Journal of Perinatology entitled 'Recommended Standards for Newborn intensive care unit (ICU) Design'. These standards were suggested in the first supplement (December 1999) by a committee, which was organized under the leadership of Robert White, MD, to establish recommendations based upon current evidence. This consensus committee continued its research and in January 2002 met again at Stan Gravin's conference entitled 'The Physical and Developmental Environment of the High-Risk Infant'. The second supplement was published in the Journal of Perinatology in January 2003. This third supplement bearing the same title details the report of this committee which again met at the same conference in January 2006.

This Sixth Consensus Committee remains multidisciplinary and consists of physicians, nurses, architects, health care administrators, interior designers, state planning officials, engineers, attorneys and $\mathrm{PhD}$ specialists with expertise in many areas. The opinions and recommendations, which are presented, are based upon an understanding of newborn physiology and the environmental factors, which make adaptation a necessity. Many advancements have been made over the years in understanding the role of the physical environment, the family and the health care team in providing care to the newborn and to improve short and long-term morbidity. We are more cautious in making recommendations unless there is evidence-based information, which offers support. Technology proliferates, science and families converge and 'therapeutic exuberance' often promotes advancement.

This supplement differs from the others in several aspects. There has been incorporation of an International Advisory Committee, which broadened the scope of the material. The standards are stated and the interpretation commentary, which follows, is clear and concise. An excellent reference list is also provided. There is also supplemental material detailing the impact of single family rooms (Debra Harris), the acoustical environmental (Kathleen Philbin), strategies for access to nature (Mardelle Shepley), the selection of appropriate materials for sustainable design (Anna Marshall-Baker) and the background material necessary for selecting appropriate lighting and flooring (Mark Rea).

This supplement will provide the reader a guide for new neonatal ICU design or re-design of an already established facility. As is stated in the Introduction 'It is our hope that this document will continue to provide the basis for a consistent set of standards that can be used by all states and endorsed by appropriate national organizations, and that it will also continue to be useful in the international area'.

I believe that these recommended standards have continued to 'light the candles' necessary to provide the optimal environment for the newborn infant and that we will 'curse the darkness' less often. 